\title{
Karakteristik Koproduk Grup Hingga
}

\author{
Edi Kurniadi, Stanley P.Dewanto, Alit Kartiwa \\ Jurusan Matematika FMIPA Universitas Padjadjaran \\ Jalan Raya Bandung Sumedang KM 21 Jatinangor 45363 \\ Email: edi.kurniadi@unpad.ac.id, stanleypd@bdg.centrin.net.id, \\ alit_kartiwa@yahoo.com.
}

\begin{abstract}
ABSTRAK
Dalam makalah ini diteliti bagaimana mengkonstruksi koproduk dari dua buah grup. Lebih jauh diteliti sifat-sifat yang dimiliki oleh koproduk dan kaitannya dengan hasil kali langsung. Sifat yang sangat menarik dalam penelitian ini adalah hasil kali bebas grup-grup hingga yang tidak mengawetkan keterhinggaan.

Kata kunci : koproduk, hasil kali langsung, hasil kali bebas.

\section{ABSTRACT}

In this paper we do a research about how to construct a coproduct from two groups. Further, we insvetigate the coproduct's properties and a relation to a direct product. The interested property of free product of finite groups that does not preserve a finiteness.

Keywords: coproduct, direct product, free product.
\end{abstract}

\section{Pendahuluan}

Fokus utama dalam makalah ini adalah meneliti sifat-sifat koproduk dari grup hingga yang tidak mengawetkan keterhinggaan. Hal ini berbeda dengan karakteristik yang dimiliki oleh hasil kali langsung. Hal pertama yang dilakukan adalah mengonstruksi suatu koproduk melalui diagram komutatif dari suatu hasil kali langsung sebagaimana telah dikembangkan oleh Laszlo Fuchs [8] dan Brian Osserman [5]. Selanjutnya didefinisikan grup bebas yang mempunyai generator berbentuk pasang terurut dan grup bagian yang dibangun oleh generator tertentu. Dalam hal ini, koproduk akan didapatkan dari produk langsung sebagai dualnya.

Dalam Allenby dan Tang [1] telah diperoleh grup bagian Frattini sebagai perluasan dari koproduk yang menunjukkan bahwa koproduk selalu mempunyai grup maksimal. Selain itu, dalam Azarian [3] telah didapat grup bagian near Frattini dari perluasan koproduk. Dalam makalah berikutnya Allenby [2] juga telah membuktikan grup bagian upper Frattini dari perluasan koproduk. Deskripsi di atas telah menunjukkan bahwa koproduk sangat penting dalam grup bagian Frattini dan sejauh ini karakteristik koproduk dari grup-grup hingga yang tidak mengawetkan keterhinggaan belum ada yang membahas secara detail. Aplikasi koproduk bisa digunakan untuk mempelajari struktur yang berkaitan dengan dualisasi seperti aljabar dan koaljabar yang telah dibahas oleh Kurniadi dan Irawati, [7]. Aplikasi lainnya telah diterapkan 
oleh Azarian [4] seputar grup bagian Frattini dan beberapa kajian yang dilakukan Dauns [6]. Termotivasi oleh kajian-kajian di atas, dalam makalah ini diteliti tentang sifat-sifat koproduk dari grup hingga yang tidak mengawetkan keterhinggaan.

\section{Metode Penelitian}

Metode penelitian dalam makalah ini berupa kajian terhadap jurnal matematika khususnya dalam bidang aljabar.

\section{Hasil dan Pembahasan}

\section{Sifat-Sifat Hasil Kali Dan Jumlah Langsung}

Beberapa sifat yang dikaji dalam makalah ini erat kaitannya dengan diagram komutatif dan hasil kali dan jumlah langsung . Berikut definisi formal diagram komutatif

Definisi 1. (Massey [8]) Suatu diagram dikatakan komutatif jika didapatkan komposisi homomorfisma yang sama ketika mengikuti arah panah sepanjang jalur yang berbeda dari satu grup ke grup yang lain dalam diagram.

Sebagai contoh perhatikan gambar berikut

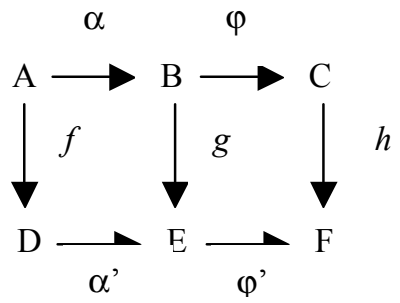

Gambar 1. Diagram komutatif grup

Dari Gambar 1 di atas, akan diperoleh kesamaan homomorfisma $h \varphi \alpha, \varphi g \alpha$, dan $\varphi \quad \alpha \quad f$. Oleh karenanya, Gambar 1 di atas komutatif.

Diagram komutatif ini digunakan untuk mengonstruksi koproduk yang lebih detail dijelaskan dalam pembahasan.

\section{Hasil Kali Langsung}

Untuk sembarang keluarga modul $M_{i}, i \in I$, diindeks oleh himpunan indeks sembarang. Produk $\prod M_{i}$ dapat dipandang sebagai :

1. Himpunan semua fungsi $\alpha, \beta: I \rightarrow \cup\left\{M_{i} \mid i \in I\right\}$ sedemikian sehingga $\alpha(i) \in M_{i}$ untuk semua $i$, dengan operasi $R$-modul didefinisikan titik demi titik yaitu $(\alpha-\beta)(i)=\alpha(i)-\beta(i)$ dan $(\alpha r)(i)=\alpha(i) r$ untuk semua $i \in R$.

2. Semua strings atau himpunan 


$$
x=\left\{x_{i} \mid i \in R\right\} \equiv\left(x_{i}\right) \equiv\left(\ldots, x_{i}, \ldots\right), x_{i} \in M_{i}
$$

Sedangkan direct sum $\oplus\left\{M_{i} \mid i \in I\right\} \equiv \oplus M_{i}$ didefinisikan sebagai modul bagian dari $\prod M_{i}$ yang memuat semua elemen berbentuk $x=\left(x_{i}\right) \in \prod M_{i}$ yang mempunyai sejumlah hingga komponen $x_{i}$ tak nol.

\section{Sifat Universal Hasil Kali dan Jumlah Langsung}

Ada dua sifat mengenail jumlah langsung sebagai berikut

i. Misalkan $\oplus M_{i} \subseteq \prod M_{i}, j_{k}$ dan $\pi_{k}: \prod M_{i} \rightarrow M_{k}$ yang didefinisikan oleh $\pi_{k}\left[\left(x_{i}\right)_{i \in I}\right]=x_{k}$. Untuk sembarang modul $A$ dan $R$-homomorfisma $g_{k}: A \rightarrow M_{k}$ untuk semua $k \in I$ terdapat secara tunggal $R$-homomorfisma $g: A \rightarrow \prod M_{i}$ sedemikian sehingga $\pi_{k} g=g_{k}$ untuk semua $k \in I$

ii. Untuk sembarang modul $B$ dan $R$-pemetaan $h_{k}: M_{k} \rightarrow B, k \in I$, terdapat secara tunggal $R$-pemetaan $h: \bigoplus M_{i} \rightarrow B$ sedemikian sehingga $h j_{k}=h_{k}$ untuk semua $k \in I$

\section{Tinjauan terhadap Hasil Kali Tensor}

Pendefinisian koproduk identik dengan pendefinisian hasil kali tensor sebagaimana telah dibahas dalam Kurniadi dan Irawati [7]. Dalam makalah ini penulis melakukan suatu tinjauan ulang terhadap hasil kali tensor dari dua buah modul atas gelanggang.

Definisi 2 (Dauns [6]) Misalkan $A_{R}$ dan ${ }_{R} B$ berturut-turut menyatakan $R$ modul kanan dan kiri. Jika $U$ menyatakan grup Abelian aditif, maka $\phi: A \times B \rightarrow U$ dikatakan pemetaan balance jika dipenuhi :

1. $\varphi\left(a_{1}+a_{2}, b\right)=\varphi\left(a_{1}, b\right)+\varphi\left(a_{2}, b\right)$

2. $\varphi\left(a, b_{1}+b_{2}\right)=\varphi\left(a, b_{1}\right)+\varphi\left(a, b_{2}\right)$

3. $\varphi(a r, b)=\varphi(a, r b)$,

untuk semua $a, a_{1}, a_{2} \in A, b, b_{1}, b_{2} \in B$ dan $r \in R$.

Kondisi (1) dan (2) mengatakan bahwa $\varphi$ suatu pemetaan bilinier.

Dapat ditunjukkan bahwa jika $\eta: U \rightarrow U$ suatu homomorfisma grup maka pemetaan komposisi $\eta \varphi: A \times B \rightarrow U$ suatu pemetaan balance.

Jika $A_{R}$ dan ${ }_{R} B$ sebarang $R$-modul, definisikan $S=\mathbf{S}(A, B)$ menjadi grup komutatif bebas atas $A \times B$. (Grup komutatif bebas artinya jumlah langsung dari pembangun suatu grup siklik tak hingga dan $A$ x $B$ memuat semua pembangun dari $S$. Dalam hal ini $S=\oplus<\left(a_{\mathrm{i}}, b_{\mathrm{i}}\right)>$ dengan $\left.i \in \mathrm{I}\right)$. Dengan kata lain, setiap unsur di $S$ dapat ditulis secara tunggal sebagai suatu jumlah hingga $\sum z_{\mathrm{a}, \mathrm{b}}(a, b)$ dengan $z$ bilangan bulat.

Misalkan $H$ subgrup dari $S$ yang dibangun oleh unsur-unsur dengan bentuk sebagai berikut:

1. $\left(a_{1}+a_{2}, b\right)-\left(a_{1}, b\right)-\left(a_{2}, b\right)$ 
2. $\left(a, b_{1}+b_{2}\right)-\left(a, b_{1}\right)-\left(a, b_{2}\right)$

3. $(a r, b)$ - $(a, r b)$, untuk semua $a, a_{1}, a_{2} \in A, b, b_{1}, b_{2} \in B$ dan $r \in R$.

Sekarang didefinisikan $A \otimes B$ menjadi suatu grup komutatif aditif $S / H$. Untuk $(a, b) \in S$, didefinisikan $a \otimes b=(a, b)+H=1(a, b)+H \in A \otimes B$. Restriksi pada $S \rightarrow S / H$ oleh $A \times B$ menghasilkan pemetaan $\quad \phi: A \times B \rightarrow A \otimes B$. Berdasarkan pendefinisian $H$ di atas dapat dilihat bahwa $\phi$ suatu pemetaan balance.

Dari konstruksi di atas dapat diperoleh definisi hasilkali tensor sebagai berikut :

Definisi 3 (Dauns [6]) Untuk modul $A_{R}$ dan ${ }_{R} B$ atas suatu ring $R$, suatu hasilkali tensor dari $A$ dan $B$ adalah pasangan $(T, \varphi)$ dimana $T$ adalah grup komutatif dan $\varphi: A x B \rightarrow T$ suatu pemetaan balance. Untuk sebarang pemetaan balance $f: A x B \rightarrow C$ ke sebarang grup komutatif $C$, terdapat homomorfisma grup komutatif yang tunggal $f^{\prime}: T \rightarrow C$ sedemikian sehingga $f$ $=f^{\prime} \varphi$.

Diagramnya dapat dilihat sebagai berikut :

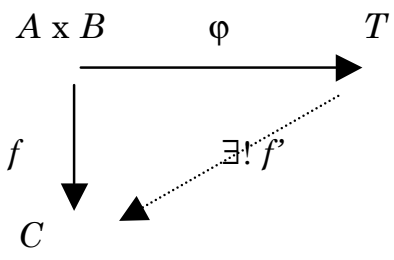

Gambar 2. Diagram hasil kali tensor

Proposisi 1 (Dauns [6]) Misalkan $A_{R}$ dan ${ }_{R} B$ adalah $R$-modul. Maka $\left(A \Theta_{R} B, \theta\right)$ suatu hasilkali tensor dari $A$ dan $B$ atas $R$. Lebih jauh, jika $\left(X, \theta^{\prime}\right)$ sebarang hasilkali tensor lain, maka terdapat isomorfisma grup komutatif $\sigma: A \otimes B \rightarrow X$ sedemikian sehingga $\theta^{`}=\sigma \theta$.

\section{Bukti :}

Dapat ditunjukkan bahwa $A \otimes_{R} B$ suatu grup komutatif dan $\theta: A \times B \rightarrow A \otimes B$ suatu pemetaan balance. Sekarang, misalkan $\varphi: A \times B \rightarrow U$ sembarang pemetaan balance. Karena $S$ modul bebas atas $A \times B$, pengaitan $(a, b) \mapsto \varphi(a, b)$ menentukan suatu homomorfisma $\eta: S \rightarrow U$. Karena $\varphi$ pemetaan balance maka $\eta$ memetakan setiap generator dari $H$ ke nol atau $\eta^{\prime}(H)=0$. Jadi, $\mathrm{H} \subset$ $\operatorname{ker}\left(\eta^{\prime}\right)$. Dari teorema isomorfisma grup terdapat $\eta: S / H \rightarrow U$ sedemikian sehingga $\eta[(a, b)+H]=\eta^{\prime}[(a, b)]=\varphi(a, b)$. Tetapi dari pendefinisian awal $S / H=$ $A \otimes B$ dan $(a, b)+\mathrm{H}=\mathrm{a} \otimes \mathrm{b}$. Oleh karenanya, $\eta: S / H=A \otimes B \rightarrow U$ suatu homomorfisma dengan $\eta(a \otimes b)=\varphi(a, b)$.

Berikut akan ditunjukkan bahwa $\eta$ tunggal. 
Misalkan $f: A \otimes B \rightarrow U$ suatu homomorfisma grup komutatif lain sehingga $\varphi=$ $f \theta$. Ambil $\xi$ unsur di $A \otimes B$ dan tuliskan $\xi=\sum a \otimes b$, yaitu jumlah hingga. Sekarang perhatikan, $f(\xi)=\Sigma f \theta(a, b)=\sum \varphi(a, b)=\eta(\xi)$. Hal ini menunjukkan bahwa $\eta=f$.

\section{Konstruksi Koproduk}

Diberikan dua buah grup $G$ dan $H$. Koproduk adalah grup $G * H$ dengan homomorfisma $i_{G}: G \rightarrow G * H$ dan $i_{H}: H \rightarrow G * H$ sedemikian sehingga jika diberikan sembarang grup $X$ dengan homomorfisma $f_{G}: G \rightarrow X$ dan homomorfisma $f_{H}: H \rightarrow X$ maka ada secara tunggal homomorfisma $f_{G} * f_{H}: G * H \rightarrow X$

Secara diagram dapat ditunjukkan sebagai berikut :

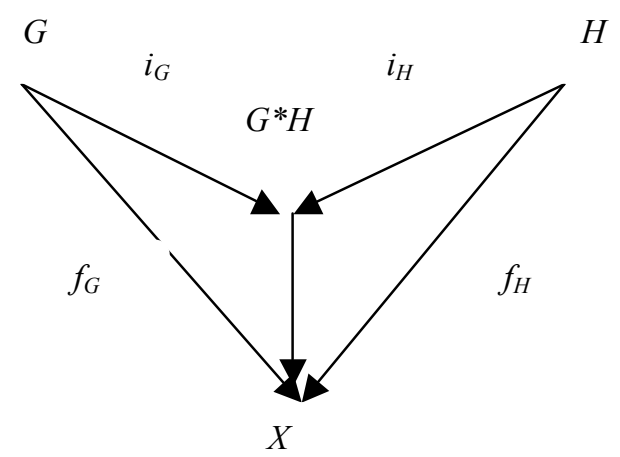

Gambar 3. Konstruksi koproduk

Di sini dapat ditunjukkan bahwa untuk sembarang grup $G * H$, dapat ditentukan secara tunggal hingga isomorfisma. Selanjutnya akan diberikan suatu contoh grup yang memenuhi sifat ini.

Misalkan $i_{G}$ suatu monomorfisma yaitu homomorfisma yang satu-satu. Ganti $X$ dengan $G$ sehingga $f_{G}$ menjadi identitas di $G$. Selanjutnya $f_{H}$ menjadi homomorfisma trivial yaitu mengaitkan semua unsur $H$ ke identitas di $G$. Dapat ditunjukkan bahwa $\operatorname{Ker}\left(i_{G}\right) \subseteq \operatorname{Ker}\left(i_{G} \circ f_{G} * f_{H}\right)$. Tetapi komposisi ini haruslah homomorfisma identitas di $G$ yang mempunyai trivial kernel dan haruslah $i_{G}$. Dengan kata lain peta dari $G$ dan $H$ terletak di $G * H$.

Selanjutnya, diperiksa relasi antara unsur $G$ yang terletak di $G * H$ dengan unsur $H$ yang terletak di $G * H$. 
Gantikan $X$ dengan $F_{2}$ dan misalkan mengaitkan semua unsur $G$ dengan pangkat dari generator $a$ yaitu didefinisikan suatu homomorfisma dari $G$ ke $F_{1} \cong \mathbb{Z}$. Sementara $f_{H}$ mengaitkan semua unsur di $H$ ke suatu pangkat dari generator $b$. Jika ada relasi antara unsur $G$ dan $H$ di $G * H$, maka tidak dapat terpenuhi sifat universal. Oleh karenanya, $G * H$ isomorf dengan $F_{2}$, hanya sebagai pengganti pergantian pangkat $a$ dan $b$ dari unsur-unsur di $G$ dan $H$. Di sini diperoleh bahwa unsur-unsur di $G * H$ berbentuk $g_{1} h_{1} g_{2} h_{2} \ldots g_{k} h_{k}$.

Hasil dari koproduk sangat berperan dalam aljabar topologi seperti dalam tulisan Massey [9].

\section{Koproduk Grup Hingga Tidak Mengawetkan Keterhinggaan}

Misalkan $G=\left\langle R_{g} \mid S_{G}\right\rangle$ penyajian untuk grup $G$ dengan $R_{g}$ himpunan semua generator untuk $G$ dan $S_{G}$ himpunan semua relasinya. Hal yang sama dilakukan untuk grup $H$ yaitu penyajiannya $H=\left\langle R_{H} \mid S_{H}\right\rangle$.

Sesuai dengan konstruksi di atas diperoleh bahwa

$$
G * H=\left\langle R_{g} \cup R_{H} \mid S_{G} \cup S_{H}\right\rangle
$$

Yaitu grup hasil koproduk $G * H=\left\langle R_{g} \cup R_{H} \mid S_{G} \cup S_{H}\right\rangle$ dibangun oleh generator $G$ bersama-sama dengan generator $H$, dengan relasi dari $G$ bersama-sama dengan relasi dari $H$.

Sebagai contoh pandang grup siklik $G$ dengan order 4 yang disajikan dalam bentuk $G=\left\langle x \mid x^{4}=1\right\rangle$ dan grup siklik $H$ dengan order 5 dengan penyajian $G=\left\langle y \mid y^{5}=1\right\rangle$. Sesuai dengan konstruksi di koproduk diperoleh

$$
G * H=\left\langle x, y \mid x^{4}=y^{5}=1\right\rangle
$$

Perhatikan bahwa $G * H=\left\langle x, y \mid x^{4}=y^{5}=1\right\rangle$ penyajian dari grup dihedral tak hingga.

Teorema 1.(Brian [5]) Misalkan $G$ dan $H$ grup hingga maka $G * H$ selalu tak hingga.

Bukti : Konstruksi koproduk $G * H=\left\langle R_{g} \cup R_{H} \mid S_{G} \cup S_{H}\right\rangle$ dengan $R_{g}$ himpunan semua generator untuk $G$ dan $S_{G}$ himpunan semua relasinya. Hal yang sama dilakukan untuk grup $H$ yaitu penyajiannya $H=\left\langle R_{H} \mid S_{H}\right\rangle$. Telah dijelaskan pada konstruksi koproduk $G * H$ bahwa unsur-unsur nontrivial dari grup $G$ dan $H$ tidak komutatif satu sama lain maka $G * H=\left\langle R_{g} \cup R_{H} \mid S_{G} \cup S_{H}\right\rangle$ tak hingga.

\section{Simpulan}

Telah diberikan bagaimana mengkonstruksi koproduk dari dua buah grup. Sifat dari koproduk dua buah grup hingga yang tidak mengawetkan keterhinggan juga telah dibuktikan dalam Teorema 1 berikut contohnya. Untuk penelitian lanjutan dapat dikaji generalisasi koproduk dua buah grup 
dengan produk amalgamated berikut penerapan koproduk dalam masalah sinyal dan sistem.

\section{Daftar Pustaka}

1. Allenby and Tang, 1974, On the frattini subgroups of generalized free products, Bull. Amer. Math. Soc., 80, 119-121

2. Allenby,2005, On the upper near Frattini subgroup of the generalized free product, Houston J. Math., 31, no 4, 999-1005

3. Azarian, 2006, Subgroups of certain generalized free products of groups, International Journal of Pure and Applied Mathematics, Vol 28, No.3, pp. 337-385. Mathematical Reviews, MR2230953(2008b:20032), February 2008, p.1056. Zbl 1122.20011

4. Azarian, 2011, Conjectures and questions regarding Near Frattini Subgroups of generalized free products of groups, International Journal of Algebra., no. 1, $1-15$

5. Brian Osserman, 1990, Free Products and amal gamated products.

6. Dauns, John, 1994, Modules and Rings, Cambridge University Press.

7. Kurniadi dan Irawati, 2007, Aljabar atas suatu lapangan dan dualisasinya, Institut Teknologi Bandung.

8. Laszlo Fuchs, 1970, Infinite Abelian Groups. 252-274.

9. Massey, 1967, Algebraic Topology : An introduction, Springer Verlag, New York. 